\title{
ABOUT WEB-BASED DISTANCE LEARNING
}

\author{
Tinatin Mshvidobadze and Tamar Gogoladze \\ tinikomshvidobadze@yahoo.com \\ tamilagogoladze@gmail.com \\ Gori University, Chavchavadze street, Georgia
}

\begin{abstract}
This paper reviews the status of natural resources distance learning programs in both the United States and China and evaluation of the feasibility for American higher education institutions to extend such programs to students in China. Computer-based learning programs were reviewed for a random sample of 300 American colleges and universities. A short fact-finding trip to China was conducted to visit 7 Chinese to obtain information.
\end{abstract}

\section{KEYWORDS:}

Higher education, random numbers, distance learning degrees.

\section{INTRODUCTION}

Distance learning" is where most or all of the learning by the student occurs outside the traditional classroom, through the use of paper resources, video, teleconferencing, Computer Managed Learning (CML), or on-line courses on the Internet. The terms "distance learning," "distance education," "distributed learning," "correspondence," "home study," "cyber school" and "independent study" have almost identical meanings.

Virtual education is a form of learning that can best achieve the parameters established for a life long learner. It allows for the necessary flexibility in developing methods of delivery that satisfies the intellectual needs of the student. Utilizing a blend of asynchronous and synchronous interaction through a variety of technologies, many of the learning activities that occur in face to face traditional classrooms can be employed.

Depending on the organizational structure of the school division, leadership could arise from any of the educational partners involved. Once that leader(s) emerge, Anderson suggested that the policy makers consider such factors as:

$>$ Assessing the present state of technology and future needs.

$>$ Providing ongoing evaluation and assessment.

$>$ Identifying educational institutions that have established and implemented technological classrooms for planning members to visit.

$>$ Attending conferences and other professional development opportunities that would enable planning members to gather new insights into how technology could be used in the classroom.

$>$ Determining how often the planning team will meet.

$>$ Assigning planning responsibilities to team members. 
Modern distance education initially relied on the development of postal services in the 19th century and has been practiced at least since Isaac Pitman taught shorthand in Great Britain via correspondence in the 1840s. The University of London claims to be the first university to offer distance learning degrees, establishing its External Programmed in 1858. This program is now known as the University of London International Programmed and includes Postgraduate, Undergraduate and Diploma degrees created by colleges such as the London School of Economics, Royal Holloway and Goldsmiths. In the United States William Rainey Harper, first president of the University of Chicago developed the concept of extended education, whereby the research university had satellite colleges of education in the wider community, and in 1892 he also encouraged the concept of correspondence school courses to further promote education, an idea that was put into practice by Columbia University. In Australia, the University of Queensland established its Department of Correspondence Studies in 1911 [1].

More recently, Charles Wedemeyer of the University of Wisconsin-Madison is considered significant in promoting methods other than the postal service to deliver distance education in America. From 1964 to 1968, the Carnegie Foundation funded Wedemeyer's Articulated Instructional Media Project (AIM) which brought in a variety of communications technologies aimed at providing learning to an off-campus population. According to Moore's recounting, AIM impressed the UK which imported these ideas when establishing in 1969 The Open University, which initially relied on radio and television broadcasts for much of its delivery. Athabasca University, Canada's Open University, was created in 1970 and followed a similar, though independently developed, pattern. Germany's Fern Universities in Hagen followed in 1974 and there are now many similar institutions around the world, often with the name Open University (in English or in the local language). All "open universities" use distance education technologies as delivery methodologies and some have grown to become 'mega-universities', a term coined to denote institutions with more than 100,000 students.

The development of computers and the internet have made distance learning distribution easier and faster and have given rise to the 'virtual university, the entire educational offerings of which are conducted online. In 1996 Jones International University was launched and claims to be the first fully online university accredited by a regional accrediting association in the US.

In 2006, the Sloan Consortium, a body which arguably has a conflict of interest in the matter, reported that: More than 96 percent of the very largest institutions (more than 15,000 total enrollments) have some online offerings, which is more than double the rate observed for the smallest institutions and that almost 3.2 million US students were taking at least one online course during the fall term of 2005. A study published in 2011 by the U.S. Department of Education found that "From 2000 to 2008, the percentage of undergraduates enrolled in at least one distance education class expanded from 8 percent to 20 percent, and the percentage enrolled in a distance education degree program increased from 2 percent to 4 percent."

Today, there are many private and public, non-profit and for-profit institutions worldwide offering distance education courses from the most basic instruction through to the highest levels of degree and doctoral programs. Levels of accreditation vary: some of the institutions receive little outside oversight, and some may be fraudulent diploma mills, although in many jurisdictions, an institution may not use terms such as "university" without accreditation and authorization, often overseen by the national government - for example, the Quality Assurance Agency in the UK. In the US, the Distance Education and Training Council (DETC) specializes in the accreditation of distance education institutions [2]. The types of available technologies used in distance education are divided into two groups: synchronous learning and asynchronous learning. 
Synchronous learning technology is a mode of delivery where all participants are "present" at the same time. It resembles traditional classroom teaching methods despite the participants being located remotely. It requires a timetable to be organized. Web conferencing, videoconferencing, educational television, Instructional television are examples of synchronous technology, as are direct-broadcast satellite (DBS), internet radio, live streaming, telephone, and web-based VoIP.

The asynchronous learning mode of delivery is where participants access course materials on their own schedule and so is more flexible. Students are not required to be together at the same time. Mail correspondence, which is the oldest form of distance education, is an asynchronous delivery technology and others include message board forums, e-mail, video and audio recordings, print materials, voicemail and fax.

The two methods can be combined in the delivery of one course. For example, some courses offered by The Open University use periodic sessions of residential or day teaching to supplement the remote teaching.

Other technology methods used in the delivery of distance education include online threedimensional (3D) virtual worlds. A popular 3D virtual world, active worlds, is used for synchronous and asynchronous learning. Active Worlds provides opportunities for students to work collaboratively.

Distance learning, which distributes knowledge to students far and near; would provide the flexibilities needed to meet new demands of the changing student population.

The actuality of using computer technologies in the humanities. There are two ways of computer technologies in teaching literature of different countries:

a. In organizing the process of lecture beforehand.

b. Including in the process of lecture video material of the according texts, extracts of texts or author's biographies and their creative lives.

Using the both methods depends on the material used in lecturer's syllabus, the author who has to be discussed with video information of hi/her creative work and the lecturer's advantage of using computer technologies.

Since the United States, the world's most industrialized nation, and China, the country with the fastest economic growth, together consume a significant amount of the earth's natural resources, the two countries should begin working together to address some of the global environmental issues. Such collaboration will be mutually beneficial to both countries if a mechanism can be established to extend natural resources distance learning from the United States to students in China. In any case, despite the aforementioned barriers, globalization of educational programs will likely be an inevitable outcome of technological trends.

\section{Educational technology aims to improve education}

Numerous colleges and universities throughout the world are developing various types of distance education programs: United State -Stanford University, England -Oxford University, CanadaUniversity of Victoria, Australia- University of Canberra, Japan - Waseda University, China Tshinghua University.

Distance learning in the United States and China, the two most influential countries in the world from the perspectives of economic strength and the urgent need for natural resources conservation, are the principal focus of this paper. With its fast economic development and rapid 
population growth, China faces both opportunities and challenges in natural resources conservation. A partnership with China is good for the United States in assuming overall world leadership (Chow 2005). Furthermore, China's management of its natural resources has great impacts and important implications not only for China but for the whole world. The 2008 dust storm from western China (Brown 2006a, Chao 2007) left the people in Korea literally gasping for breath. Schools were closed in Seoul, and airline flights were cancelled.

Objectives: By comparing the computer-based online learning programs at 300 colleges and universities in the United States and 7 higher education institutions in China, this paper discusses potential cooperation between the two countries to promote natural resources education via international distance learning.

Method: According to the National Center for Education Statistics (NCES 2005), there are 4,197 two-year and four-year education institutions in the United States. About 56\% of these institutions have distance learning programs (Tabs 2007). In an attempt to evaluate the feasibility for the colleges and universities in the United States to provide natural resources distance learning programs to students in China, or the opportunity for Chinese students to take natural resources courses offered in either country, a sample of institutions in United States was taken from the China Education and Research Network (CERNET Website a), which lists1,544 U.S. institutions with hyperlinks to their websites. The survey was also undertaken to determine the number and type of courses offered online and the amount of tuition charged by various colleges and universities for distance learning courses in both the United States and China.

To select the random sample, the aforementioned 1,544 institutions were listed in alphabetical order and numbered accordingly. Random numbers were generated on the Internet (Random.org) to select institutions for this investigation. Following the order of the random numbers, 300 colleges and universities, approximately a 20 percent sample, were chosen from the numbered list. To determine if the sample size was adequate, the samples were divided into 10 groups with 30 institutions in each group, and the cumulative frequencies of occurrence of natural resources distance learning programs were examined graphically. After reviewing the data for about 120 institutions in the sample of 300, a pattern of data consistency was observed. The frequency of natural resources distance learning courses provided by institutions ranges from $3.3 \%$ to $5.6 \%$. The mean was about $4.5 \%$, with a standard deviation of 0.01 . These results confirmed that the sample data were adequate for making some general inferences. The sample size of 300 was therefore deemed to be adequate to make inferences about distance learning programs in the United States [3].

The first step in the study was to determine the percentage of colleges and universities providing accredited distance learning courses in the sample (DL in Univ). The second step was to determine, within the sample set, the number of colleges and universities providing natural resources courses in distance learning (NRDL in Univ).

Criteria for defining natural resources courses were developed with input from faculty members at the University of Idaho, Northern Arizona University, and Virginia Tech, all members of the Natural Resources Distance Learning Consortium. A composite list of key words was used in the Internet search, such as forest, natural resources, range, wildlife, environmental science, fisheries, recreation/tourism, soils, conservation biology, ecotourism, watershed, water resources, wild land fire science, meteorology, statistics natural resources, environmental education, GIS, conservation studies, and human dimensions of natural resources.

Among the 300 sampled colleges and universities, 13 (4.5\%) offer natural resources distance learning programs that include a total of 78 courses. If this finding is extrapolated to the entire sample of 1,544 colleges and universities, an estimate can be made that 67 institutions offer 
natural resources distance learning programs and provide a total of 401 natural resources courses via distance learning. If the finding is further extrapolated to the 4,197 two-year and four-year higher education institutions in the United States, there might currently be as many as 1,091 natural resources distance learning courses available in this country.

Due to the lack of adequate information regarding China's natural resources education and the difficulty of accessing Chinese universities' websites, I conducted a short fact-finding trip to Beijing and Lanzhou to understand the status of distance learning programs developed in some of the leading institutions in China. This trip started on November 15 and ended on December 5, 2005. The data collected in China were compared with similar data for U.S. institutions offering distance learning in natural resources conservation. Other information was obtained from individuals while visiting in China or accessed Chinese websites.

Natural Resources Distance Learning Programs in United States. The sample of 300 higher education institutions revealed that 164 colleges and universities (about 55.3\%) offer accredited online courses. The $55.3 \%$ of sampled universities and colleges offering distance learning courses is close to the national average obtained by the National Center for Education Statistics (Tabs 2007). The national study found that $56 \%$ of two-year and four-year degree-granting institutions offer distance learning courses (Tabs 2007). Online courses provided by the sampled institutions are mostly in business management, computer technology, education, health care, marketing, nursing, and social science. For example, Stanford University (www.stanford.edu) offers several master degree programs, including a Master of Computer Science, Master of Electrical Engineering, and Master of Mechanical Engineering. The University of Phoenix (http://degrees.uofphx.info/programs.jsp), the most popular online university, provides several master and doctoral degree programs, including a Master of Arts in Education, Master of Business Administration, Master of Science in Computer Information Systems, and Doctor of Health Administration[4].

Natural resources distance learning: As previously discussed in this paper, the number of institutions with natural resources distance learning programs is comparatively low (about 4.5\%). This is a lower percentage than business management and administrative service, computer technology and information science, health professions, engineering technology, and liberal arts disciplines (NCES 2006). The reason for having a lower percentage of natural resources distance learning may be the natural resources management and conservation are not in as high demand as business management, computer technology and other disciplines. The online natural resource courses are found mainly in the following subjects: environmental law and policy, environmental science, environmental ethics, water management, biodiversity and conservation, energy, environmental education, environmental health, natural resource economy, wildlife management, land use and planning, and recreation. There are a total of 78 courses offered by 13 institutions in the sampled colleges and universities.

Programs: The United States Department of Agriculture (USDA) Forest Service started a distance learning program in the 1980s jointly with Colorado State University. The program expanded in 1996 when it was realigned with George Mason University (GMU).

This program continued at GWU until it was terminated in 2006 According to the student records (USDA/GMU 2006, the program provided 11 courses in areas of land management, recreation, and planning subjects. During the seven years since the realignment of the GMU program, more than 700 students enrolled in the Natural Resources Distance Learning Program .

To meet the continuing education needs of natural resources managers dispersed throughout the United States and elsewhere, the USDA Forest Service in 2005 initiated a Natural Resources Distance Learning Joint Venture Agreement with Virginia Polytechnic Institute and State 
University (Virginia Tech) (Evans 2005). The primary goal of the program is to provide academic degree and professional development programs and other education opportunities for employees of USDA Forest Service, and other state and federal natural resources management agencies throughout the nation.

Since many managers, administrators, and workers are dispersed among field and office sites around the country, distance learning provides an opportunity to improve their expertise at convenient times and locations. The Natural Resources Distance Learning Consortium, led by Virginia Tech, is developing a national program. Collaborative agreements with several other colleges and universities will provide high quality natural resources courses to meet educational standards and curriculum needs for natural resources education. In the future, the consortium will involve non-governmental organizations and professional societies (Evans 2007).

Currently, Virginia Tech's Natural Resources Distance Learning Consortium has five stakeholders: USDA Forest Service, Virginia Polytechnic Institute and State University, Northern Arizona University, the University of Idaho, and the University of Montana. Each of the four universities has its own unique specialization in its natural resources distance learning program. For example, Virginia Tech plans to focus mainly in federal land management; the University of Idaho offers courses primarily in restoration ecology such as fire ecology and aquatic ecology; Northern Arizona University focuses on eco-tourism and wild-land recreation courses; the University of Montana will offers courses in wildlife management and geographic information system courses (Evans 2007). This consortium organizational structure enables member universities to share resources in problem solving, and to cover more natural resources courses than any single university may be able to offer.

The Oregon State University grants online bachelor degrees in Environmental Sciences and Natural Resources, while Colorado State University, Texas A \& M University, the University of Wisconsin, Stephen F. Austin State University, and North Carolina State University also provide a variety of natural resources related programs through distance learning (He 2007a). These institutions could become potential partners with Virginia Tech's Natural Resources Distance Learning Consortium in order to provide additional concentrations that may be cost-prohibitive for one single university to offer [5].

Distance Learning in China. For a better understanding of distance learning in China, I conducted a short fact finding trip to Beijing and Lanzhou in Gansu Province: six universities and one research institution were visited (He 2007b). I also visited the Chinese Ministry of Education in Beijing. These universities were targeted as primary contacts because they are the leading universities with distance learning in China. They started distance learning programs between 2000 and 2005, but they are still at a developmental stage of distance learning practices ( $\mathrm{Li}$ 2007a). Most universities and colleges in China use web-based distance learning methods for inclass and off-campus learning (Li 2007a). Institutions in the Chinese Academy of Science system mostly use satellite one-way or two-way video/audio distance learning methods to convey courses to students (Huang 2007).

\section{Government Policy on Support for Distance Learning.}

China is beginning to place a greater emphasis on distance learning. The Chinese government and the universities in China believe that distance learning will enable

interactive teaching and learning at any time and place in a network environment, provide easy and efficient access to education resources, and improve the quality of education (Li 2007b). Developing distance learning programs may provide more people with diversified educational 
opportunities, allocate educational resources more efficiently, and accommodate the real demands of socioeconomic and cultural developments in China.

According to Ping Li (2007b), an official of China's Ministry of Education, China has listed distance learning as an important goal of its education development blueprint for the 10th FiveYear Plan (2001-2005) [6]. China has 1,062 colleges and universities (Li 2006a), and most are located in big cities and urban areas. In an attempt to extend higher education to rural areas, the Chinese Government has urged colleges and universities to develop distance learning programs in order to provide continuing education opportunities to more people by using new technologies.

Factors affecting Chinese students studying abroad. China has a long history of sending students abroad for education (Dai 2007). In spite of the growing national pride in some local educational institutions, many people still consider education in the West to be better than that available in Chinese colleges or universities. Since the rapid economic growth of the 2000s, the Chinese government has been sending more students abroad both for short-term training or longterm education at all levels in order to accommodate the nation's educational needs. Individuals are now better equipped to pass the Test of English as a Foreign Language (TOEFL), an international standard required English proficiency test for admission into a university in an English-speaking country (ETS Website), and people are also in a better financial situation to study abroad. According to a news article from the Chinese Embassy's website, an official of the Chinese Ministry of Education said that there have been more than 700,000 Chinese students studying abroad since 2001 (Chinese Embassy Website).

These students attended universities in developed countries such as the United States, Canada, England, Australia, Japan and Singapore (JSJ Website). Since there are still many Chinese students who for various reasons are unable to study abroad, an international distance learning program could be an alternative for satisfying the growing demands of these students for western education. Some students perceived that a joint academic degree or special certificate from an American university and a Chinese university will give them sufficient prestige to find a betterpaid job in China. For example, the University of Wisconsin and the Graduate School of the Chinese Academy of Science jointly provide an international EMBA program in technology innovation for governmental, institutional, and corporation decision-makers (GSCAS Website).

Distance Learning Systems: Different educational systems use different types of distance learning delivery methods (Li 2007a). The first distance learning system started in China in 1978. The China Central Radio and TV University began to use radio and television to deliver prerecorded courses. The Radio and TV University is growing rapidly today with a huge and powerful network system, which integrates TV, Internet, and satellite systems together with a multi-center system to distribute courses and lectures. It has 44 centers in all provinces, and most of these learning centers are located within universities. According to its website, China Central Radio and TV University have a total of 36 disciplines with 1.46 million enrollments by the end of 2007 (CRTVU Website). Since 1998, the TV University has graduated 160,000 students from its part-time programs, most in career oriented programs such as accounting and computer sciences. The University has cooperative programs with the United States, England, and 12 other countries in the world. The rapid growth of the TV University shows that there are great needs for distance learning programs in China today. However, these programs offer only a few natural resources courses.

The second distance learning system was developed to serve all institutions under the Ministry of Education's guidance and administration. This distance learning system is now evolving from a traditional education model to web-enhanced and web-based distance education. Web-based distance learning is used for on-campus teaching and for continuing education and vocational training. 
The third distance learning system is sponsored by the Chinese Academy of Science. The Graduate School of Chinese Academy of Science has over 100 distance learning centers in all institutions within the Chinese Academy of Science system. These learning centers are not affiliated with the Ministry of Education system, but are administered by the Chinese Academy of Science. The distance learning system has a main distribution center, which is located on the main campus of China Science and Technology University in Anhui Province, with the Shanghai Education Center being a sub-center. Furthermore, there is a two-way satellite distribution center at in Changchun, along with 42 satellite receiving centers covering 66 institutions (Huang 2007). Most of their courses are delivered through a satellite. The Internet is also used as a teaching and 6learning support tool for both instructors and students. Students in the Graduate School are affiliated with institutions in the Chinese Academy of Science system, which provides financial support (GSCAS Website).

Programs: In developing the distance learning programs, most of the universities in China are taking into consideration the realities of the job market and the future employment potential for their students (Li 2007a). The current distance education programs offer courses in such popular fields as finance, management, marketing, law, business, computer technology, and language art. However, natural resources related courses are not widely offered by the universities that I visited in China (He 2007b). China appears to be offering similar distance learning courses as the United States.

Based on my search of websites in China, natural resources disciplines are mostly offered in forestry universities. There are four forestry universities in China, i.e., Northeast Forestry University, Beijing Forest University, Southwest Forest University and Central Forest University, which are located respectively in the northern, northeast, southwest and central regions of China. By using web searches, I was able to find natural resources courses via distance learning for Northeast Forest University and Beijing Forest University. However, the websites for Southwest Forest University and Central Forest University could not be easily accessed from the United States [7].

\section{Discussion: Importance of Natural Resource Education.}

Natural resources education is essential for conservation and management of natural resources to achieve a sustainable society in the future (Bowers 2002). Today, the world is facing natural resources challenges along with issues of global population growth, global warming, climate change, land degradation, deforestation, habitat deterioration, air and water pollution, and desertification (Brown 2007b). These indicators are evidence that the human race is having tremendous impacts in causing global environmental changes by an over-consumption of natural resources (Goudie 2006). Global environmental changes are occurring at an accelerating pace (Cain et al.2006). Numerous authorities (Bowers 1997, Brown 2001, Raven and Berg 2007) stated that education is the key to increasing awareness of environmental problems, to change attitudes toward the environment, and to help overcome ecological challenges that humans are facing. Orr (1992:90) stated, "All education is environmental education."

Universities and colleges are responsible for educating future natural resource managers and scientists, as well as keeping natural resources professional current in their knowledge and management skills (RNRF 2007a). For example, by taking courses like conservation ecology, urban forestry, ecosystem management, and Global Issues at the Virginia Tech National Capital Region, students understand how ecosystems work, what services ecosystems can provide to us, and the importance of using natural resources in a sustainable manner. Therefore, natural resources education becomes a solution to the growing ecological crisis and leads toward ecological sustainability. 
In China, natural resources education is even more critical for its natural resource management. After 20 years of industrialization, China is now facing huge energy demands (Klare 2006). The Chinese Government has already begun the construction of the world's largest dam on the Yangzhi River in order to generate more electricity to satisfy the energy needs in the southeast part of China, an area of rapid economic growth.

Also, the accelerating expansion of the automobile industry will make China the second largest oil consumer in the world, right behind the United States (Flavin 2007). These significant developments will not only raise the level of oil consumption, but also reduce the amount of agricultural land by expanding the network of roads and highways, whichis usually followed by the construction of new business and residential buildings.

Eventually, new towns will appear as more people and industry move into the area. As a result, these developments will add more pressure to the country's environment, increase air and water pollution, and create such environmental crises as land degradation, water shortage and deforestation. With rapid population growth and limited forest resources, China will have to rely on wood importation to support its development. As Steven Johnson, a statistician of the International Tropical Timber Organization, predicted, China will surpass the United States, Japan, and the European Union as the world biggest importer of logs (Pomfret 2007). To avert potential problems, the concepts of natural resources conservation and sustainable development must be recognized and given high priority by all levels of government, as well as educators, teachers, administrators, natural resources managers, activists, company leaders and individuals.

\section{CONCLUSION:}

Distance education programs will continue to grow both in the United States and abroad. One of the reasons for this growth is related to the ever growing global need for an educated workforce combined with financial constraints of established educational systems. Distance education offers life-long learning potential to working adults and will play a significant part in educating societies around the world. Distance education will become of far greater importance in the United States in the years ahead because it is cost efficient and because it allows for independent learning by working adults. If society is to cope with this growing need for an educated workforce, distance education must continue to make its place in the educational community. A major development in the changing environment of distance education in the United States is the rise of corporate universities and commercial institutions selling academic programs.

Extending natural resources distance education to China may improve sustainable management of its resources. Although potential barriers such as technical incompatibilities, as well as language and cultural barriers must be first overcome, cooperation between the United States and China may have substantial mutual benefits for natural resources conservation.

Currently, only a few universities in China offer courses address natural resources. American universities may collaborate with their Chinese counterparts by assisting them in setting up natural resources educational programs and by extending certain natural resources distance learning courses to Chinese students. Collaboration does not necessarily mean that China will adopt the American program in its entirety.

\section{REFERENCES:}

Web site:
$\begin{aligned} & \text { 1.Best Teaching Practice (n.d.) (2004), } \\ & \text { http://www.unb.ca/current/special/teaching.html. }\end{aligned}$


International Journal of Distributed and Parallel Systems (IJDPS) Vol.3, No.3, May 2012

2. Effective Practices Toward School Plus (2002). Retrieved January 28, 2004, from http://www.sasked.gov.sk.ca/k/pecs/splus/Default.htm

3. Distance Learning Programs in Western Canada. (n.d.) (2004). Retrieved January 25, 2004, from http://www.alis.gov.ab.ca/edinfo/Content/RequestAction.asp?aspAction $=$ GetDistLearnPage $\&$ Page $=$ DistLearn .

4. ALL Online. Alliance for Lifelong Learning. www.allearn.org. Accessed November 10,2006.

5. C.A Bowers, 2006. The culture of denial: Why the environmental movement needs a strategy for reforming universities and public schools. State University of New York Press. Albany, New York.

6. Brescia, William, Michael Miller, Poda Ibahima, John Murry. 2007. Orientation practices for effective distributed learning coursework: Students speak their minds. Online Journal of Distance Learning Administration. www.westga.edu/ distance/ojdla/fall73/brescia73.html.

7. Brown, Lester. 2007. China losing war with advancing deserts. Earth Policy Institute http://www.earth-policy.org/Updates/Update26.htm

\section{Short Biography:}

Tinatin Mshvidobadze

Address: 7/33 Tskhinvali street

Gori/Georgia - 1400

tinikomshvidobadze@yahoo.com

Mobile: 898-42-20-69

\section{Education:}

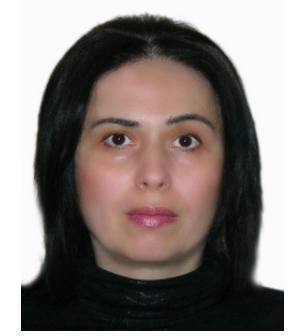

Georgian Technical University. The Department of Automatic and Calculate Technique - ComputerAided Govern Systems.

\section{Scientific-Pedagogical Working Experience:}

2007-2011 - Associated Professor at LEPL Gori (Georgia) University.

1998-2006 - Assistant at the Engineering Department of Georgian Technical University.

\section{Academic Degree and Published Works:}

Academic Degree of a Doctor. Monograph - "Informational Technologies for Economic Effect of Energetic Systems”. Book -“information technology”.

The amount of scientific works during the last 5 years - 30 .

International conference during the last 5 years - 30 .

\section{TAMAR GOGOLADZE, PH.D}

Tamilagogoladze@gmail.com

\section{ACHIEVENTS}

- Doctor of Philology - PHD thesis ,Love Lyrics in the $19^{\text {th }}$ Century Georgian

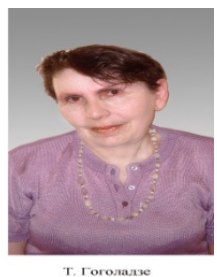
Literature" (2005)

- Liberal Arts Faculty, Head of MA programs - Gori University, Georgia.

- Holder of the Older of Honour of Georgia.

- Candidate of Philology - Candidate thesis „Soprom Mgaloblishvili’s Literary Prose” (1983).

- Editor of there books and author of articles is 34 scientific journals and about 100 periodicals and three self-designed - a collection entitled „Researches and Studies” (2008), a monograph „,on the 
International Journal of Distributed and Parallel Systems (IJDPS) Vol.3, No.3, May 2012

History of the Georgian Love Lyrics” (2003) and a publication „Vazha Pshavela's Love Lyrics” (2001)

- Member of the Shida Kartli Writers' Branch and Scientific of the Gori Historical and Ethnographic Museum.

\section{EDUCATION}

1974-1978 Tbilisi State University Postgraduate School, Specialization: New Georgian Literature.

1964-1969 Gori N. Baratashvili State Pedagogical Institute, Specialization: Georgian Language, Literature, and History.

1953-1964 Gori Railway Secondary School \#11, completed with a Gold Medal. 